\title{
Spiritual well-being and quality of life in advanced age women post-mastectomy for breast cancer operated
}

\begin{abstract}
Summary
Background: Quality of life and spiritual well-being are results reported by the patient (PRO) that have regained interest to be studied in chronic entities with a good survival rate such as breast cancer and the most common treatment of choice (mastectomy).

Objective: To evaluate spiritual well-being and quality of life in post-operated Mexican women of mastectomy.

Methods: Descriptive study, with sampled adherence to inclusion and exclusion criteria, interviewing a total of 102 elderly patients, using the instruments: Facit SP-12; Functional Assessment of Chronic Illness Therapy-Spiritual Well-Being, reliability of 0.89 ; and the Functional Assessment of Cancer Therapy-Breast or FACT-B with a reliability of 0.90 . Prior informed consent and adherence to ethical legal considerations for the Mexican population. Obtaining as results that the age of the patients with a higher percentage was 60 to 64 years old, mostly married $71 \%$, incomplete primary education $42 \%$. In terms of spiritual well-being and quality of life, it was found that the percentage that achieve nothing committed is very good quality of life $13 \%$ and very good spiritual well-being $8 \%$, in general if it was found that in its majority if there is little and regular commitment to both quality of life and spiritual well-being, aspects that require personalized nursing care were found to improve the positive response and strengthen that spiritual well-being and educational interventions to improve the quality of life.
\end{abstract}

Keywords: breast cancer, Spiritual well-being, quality of life
Volume 6 Issue I - 2019

\section{Mónica Gallegos Alvarado,' Ma Cristina Ochoa Estrada,' Mayra Guadalupe Hernández Romero, ${ }^{2}$ Martha Lilia Parra Dominguez,' Eloísa Esquivel Rodriguez, ${ }^{3}$ Sofía Elena Pérez Zumano'}

'Doctor of Nursing Sciences, Universidad Juárez del Estado de Durango, Mexico

${ }^{2}$ Bachelor of Nursing, Universidad Juárez del Estado de Durango, Mexico

${ }^{3}$ Doctor of Law, School of Nursing and Obstetrics of the Juarez University of the State of Durango, Mexico

\author{
Correspondence: Monica Gallegos Alvarado, Doctor of \\ Nursing Sciences, Juarez University of the State of Durango/ \\ School of Nursing. PROCUIDEM Office, María Fernanda \# I I7, \\ Private Fractionation Alejandro c.p 3016 Durango Dgo, Mexico, \\ Tel +526|8| I70619, Email moniga74@gmail.com \\ Mayra Guadalupe Hernández Romero, Bachelor of Nursing, \\ Universidad Juárez del Estado de Durango, 21 Alma Court, \\ Commerce Ga, Mexico, 30529 (770) 5765084, \\ Email salasmayra07@gmail.com
}

Received: September 26, 2018 | Published: February 05, 2019

\section{Introduction}

In the latest estimates published during 2018 on the global epidemiological burden of cancer, breast cancer represents the second cause of death in women, the first cause of prevalence and due to advances in multimodal treatment, it has been possible to offer less traumatic therapeutic measures in early stages, resulting in a survival of 5 or more years. ${ }^{1,2}$

In this regard, the 5 -year survival scale will be $100 \%$ in a stage 0 and I, $93 \%$ in a stage II, $72 \%$ in a stage III and $22 \%$ in a stage IV of the disease. ${ }^{3,4}$ However, it should be noted that women diagnosed with this condition must undergo a mastectomy as part of a restorative treatment, since surgery is generally the first procedure chosen against breast cancer, currently in the In developed countries, most women with breast cancer are detected in stage I or in stage II. Surgery can cure most women who have the tumor in situ and about half of all patients in stage II.

In Mexico, as in other countries of similar development, detection is delayed and decisions about surgery depend on several factors, taking into account the stage of cancer, total mastectomy may be the correct option in cases of a larger tumor of 5 centimeters. The Ministry of Health (SS), through unpublished registered statistical data, reports that in 2008 the number of mastectomies registered in Mexico was the most performed treatment, reporting a total of 3,425 mastectomies nationwide, with a frequency of scarce breast reconstructions, registering only 97 total reconstructions for the same year and the mastectomies performed by state range from 95 to 150 , with the exception of the most industrialized cities where these figures almost double as well as in the country's capital, for the following years a similar behavior has been reported only with the increase of $30 \%$ more reconstructions. ${ }^{5}$

Although breast cancer arises at a productive age, studies mention that the risk of contracting breast cancer increases with age. ${ }^{6-9}$ It is known that most cases diagnosed with breast cancer occur in women older than 60 years. However, the amputation of any part, whether external or internal to the body, is traumatic at any age, producing a radical change in the appearance of every woman, bearing in mind that in older women there are already changes due to age. and as a result the physical, emotional and social well-being are affected, important aspects of the quality of life and associated with this quality of life, another aspect that recovers importance is the spiritual wellbeing which has a unique relationship with itself and the meaning of his life, giving greater importance to said spirituality considering it as a dimension of the human being. ${ }^{10}$

No doubt the spiritual well-being and the quality of life are influenced by the physical health of the person, their psychological state, their level of independence, their social relationships, the environment and general health, 11 nursing professionals in the exercise of his profession has as a fundamental pillar the care of the health of the people so it is relevant to identify these unique aspects of people in different health situations such as breast cancer which as seen represents a health problem in the world but now thanks to scientific advances and global programs has been increased the survival time so it generates the need to address in a holistic manner and humanized care trying to avoid or reduce the different complications generated for necessary treatments such as mastectomy in any of its indications, whether it be a partial mastectomy the conservative, a total mastectomy, with or without lymph node dissection, as the only 
treatment or combined with chemotherapy and/or radiotherapy that can undoubtedly affect their quality of life and spiritual health that can be strengthened and taken care of in a timely manner for the health contribution of these people in disease-free periods.

It should be considered that women who experience a survival of more than 5 years have to face some complications either due to the disease process, treatment or associated diseases impacting their quality of life and spiritual well-being, being difficult for women people maintain their integrity in these areas, and at the same time carry the natural process of the disease and the consequences derived from a visibly mutilating treatment such as mastectomy. Data provided by the center for the control and prevention of diseases in Buford, Atlanta, show the relationship of age with the risk of breast cancer and these data affirm that $3.56 \%$ of women who are currently 60 years of age, they will get breast cancer at some point in their lives for the next 10years. This means that 3 or 4 of every 100 women who today are 60 years old will get breast cancer when they are 70 years old. ${ }^{6}$ It is therefore important to include older women in prevention, diagnosis and control programs with continued care, since very few studies have focused on this age group. ${ }^{6-15}$

After the mastectomy treatment, the woman may experience changes in family, work and personal dynamics; bringing as a consequence changes in the sphere: physical, psychological, social and spiritual. ${ }^{7}$ In turn, the quality of life that it experiences changes due to the affectation of the different aspects that compose it, such as: physical, family, social, emotional and functional well-being. In this regard, continuous nursing care is sought to be undertaken in a bio psychosocial way with special attention to the alterations related to the spiritual wellbeing and the quality of life themselves that together encompass a great part of what conforms the human being: his body, his soul and his spirit since within the multiple components of the quality of lifetime, spirituality has a marked importance when defined as: the sense of peace, purpose, connection with others and not only the beliefs it holds about what gives meaning to life. In its more defined characteristics, a high level of spirituality includes: hope, feeling free of guilt and satisfaction with life itself, these are also closely associated with a better adaptation to cancer; reducing anxiety and depression, thereby improving the quality of life. ${ }^{12}$ Thanks to the tireless struggle to improve health treatments and interventions aimed at people with life-threatening conditions, an increase has been achieved in the survival of these people, however, a greater survival; it also means greater vulnerability to a life with deficiencies which undoubtedly affects health if we consider what is written by the WHO, Health is the complete physical, mental and social wellbeing. ${ }^{10-14}$ In the same order of ideas the quality of life; defined as optimal wellbeing among the five dimensions of health: physical, mental, social, relational and spiritual at any level of health or illness. ${ }^{15}$

Assessing the spiritual well-being and quality of life in elderly women represents a contribution of substantial information for nursing staff in their task of health care considering the human being as a physical, spiritual and social being that deserves to be seen and understood as a whole, emphasizing that the care of the spiritual well-being and improvements in the quality of life in mastectomized patients can support in the treatment since it influences the grieving process and confers the physical, social and emotional support necessary to travel through the treatment and control of the disease. However, it has been recognized that care in these areas is limited and having related studies opens the possibility of providing better care either through education and the establishment of defined interdisciplinary interventions.

\section{Methods}

A quantitative, descriptive, cross-sectional, non-experimental study carried out in a state oncology specialty center in the state of Durango-Mexico, with an annual demand of 57 to 59 mastectomies, considered for the study by the people treated in 2014 to 2018 under a non-probabilistic convenience sampling, adhering to inclusion criteria regarding the age of over 60 years, without mental alterations, uncontrolled comorbidity and under informed consent respecting their anonymity, obtaining a total sample of 102 patients who compiled the acceptance criteria. During the development of the research, the provisions of the regulations of the General Law of Health in the Field of Health Research are respected, ${ }^{16}$ in the second title of ethical aspects of the investigation in human beings and in the declaration of Helsinki in its last revision. The information was collected through two instruments: FACIT-SP-12 and the FACT-B (4th version), validated in several languages and reproduced with the authorization of the author and his FACIT.org organization. ${ }^{16,17}$

Facit -SP-12 functional assessment of chronic illness therapyspiritual well-being; The 12-item spiritual well-being scale: is an instrument previously piloted in similar population obtaining internal reliability according to the Cron Bach alpha coefficient of: 0.8992 , which contains 12 items, each with five response options: $0=$ nothing, $1=\mathrm{a}$ little, $2=$ something, $3=\mathrm{a}$ lot and $4=\mathrm{a}$ lot. This instrument contains two important factors of spiritual well-being: inner peace and meaning of life. The instrument follows a positive sense in general, which means that the higher the score obtained, the better the person's spiritual well-being. . $^{46-19}$

The functional assessment of cancer therapy breast (FACT-B): is the scale of "Functional Assessment of Treatments for Breast Cancer", is a self-administered instrument with no time limit. It consists of 37 statements in "Likert" format that range between 0 ("Nothing") and 4 ("Very much"). It is a type of multidimensional scale divided into 4 sub-scales: "Physical well-being", "Social wellbeing", "Emotional well-being" and "Functional wellbeing". You can obtain scores by sub-scale and global scores. It allows access to the specific concerns of this disease. It is understood that the higher the score, the better the quality of life of the person interviewed..$^{17,18}$ Both instruments validated and with adequate reliability, so the information was captured using the statistical package for the social sciences (SPSS version 20.0)

The description of the socio-demographic variables that were of interest for the study is presented, as well as the inferential statistics that responds to the proposed objectives. The sample was formed by 102 adult women who were being treated at the Oncology Specialty Hospital Center in the state of Durango, Mexico. The age of the participants ranged between 60 and 78 years of age with an average of 64 years with a standard deviation of 6 years. They are mostly married and dedicated to the home. The minimum monthly income was 0.0 pesos and the highest of $\$ 11,000$ per month, equivalent to 559 dollars per month, which is what the minority perceives. Regarding the educational level, I predominate with $42 \%$ primary incomplete, the highest percentage dedicated to educational activities home as housewives. (Table 1) 
Table I Sociodemographic characteristics of mastectomized women of advanced age

\begin{tabular}{|c|c|c|c|c|c|}
\hline Variable & F. & $\%$ & Variable & F. & $\%$ \\
\hline Age & & & Occupation & & \\
\hline $60-64$ & 49 & 48 & Housewife & 75 & 73.5 \\
\hline $65-69$ & 32 & 31 & Retired (teacher) & 18 & 17.5 \\
\hline $70-74$ & 11 & 11 & Other & 9 & 9 \\
\hline $75-79$ & 10 & 10 & & & \\
\hline Civil status & & & Monthly income & & \\
\hline Married & 72 & 71 & $0-2750$ & 56 & 55 \\
\hline Single & 18 & 17 & $2751-5500$ & 35 & 34 \\
\hline Widow & 6 & 6 & $5501-8250$ & 9 & 9 \\
\hline Divorcee & 6 & 6 & $8251-11,000$ & 2 & 2 \\
\hline Religion & & & Level of studies & & \\
\hline Catholic & 89 & 87 & Incomplete primary & 43 & 42 \\
\hline Christian & 6 & 6 & Complete primary & 20 & 20 \\
\hline \multirow[t]{3}{*}{ Jehovahs Witness } & 7 & 7 & High school & 17 & 16 \\
\hline & & & High school & 20 & 20 \\
\hline & & & Bachelor's degree & 2 & 2 \\
\hline
\end{tabular}

Source: Cedula personally identifiable information $n=102$
To determine the level of spiritual well-being of the participating population, the factors that make up the SP-12 instrument were analyzed, finding that the study population mostly presents a "little committed" spiritual well-being (49\%). However, it should be noted that $38 \%$ of the total interviewed are at a regularly committed level and only $13 \%$ feel that they do not have any compromised aspect or that they manage to be with an integrated spiritual well-being that is to say they feel with a very good spiritual well-being (Figure 1), so that an individual evaluation of the aspects evaluated in the spiritual well-being is carried out to identify data of contribution for the investigation and first of all, in the sense of life and internal peace factor, it is deduced that the group of study has difficulty in the way to achieve mental peace and inner harmony, in relation to the sense of faith, this is relatively integrated, the population refers that has little confidence towards a positive outlook of the future and find comfort and strengthening of faith.

Regarding the quality of life of the participants, the 5 welfare dimensions were considered; General physical state of health, family and social environment, emotional state, personal functioning and other concerns. In this regard we can mention that only $9 \%$ achieve an integrated quality of life is to say without any commitment, however you can observe a little or regular commitment in similar percentages in the dimension of general physical health and family environment but Regarding the emotional state, personal functioning and other health concerns and complications is compromised and regularly compromised (Table 2).

Table 2 Dimensions of the quality of life of women in advanced age mastectomized

\begin{tabular}{|c|c|c|c|c|c|}
\hline Dimensions & Very committed (comp.) & Comp. & Regularly comp. & Little comp. & Nothing comp. \\
\hline General physical health & - & $6 \%$ & $38 \%$ & $40 \%$ & $15 \%$ \\
\hline Family and social environment & - & - & $40 \%$ & $32 \%$ & $24 \%$ \\
\hline Emotional state & - & $28 \%$ & $32 \%$ & $31 \%$ & $19 \%$ \\
\hline Personal operation & - & $7 \%$ & $77 \%$ & $8 \%$ & $8 \%$ \\
\hline Other concerns & - & $20 \%$ & $63 \%$ & $6 \%$ & $7 \%$ \\
\hline Quality of life & - & $11 \%$ & $34 \%$ & $47 \%$ & $8 \%$ \\
\hline
\end{tabular}

Source: Instrument FACT-B (4th eEdition) $n=102$

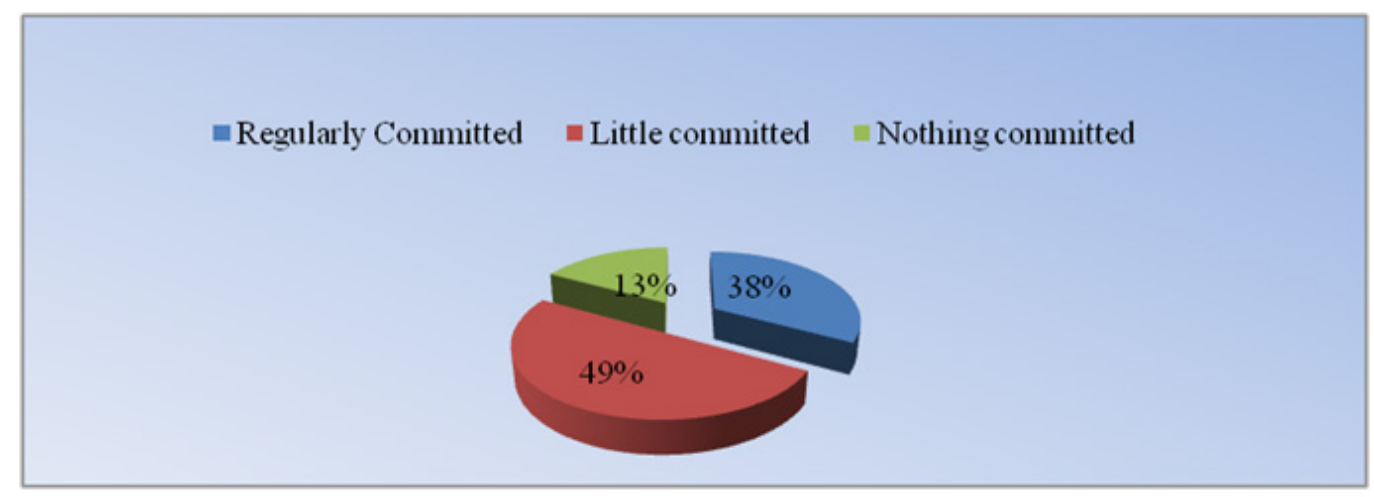

Figure I The spiritual well-being of mastectomized older women.

Source: Questionnaire SP-12 (4th version) $n=102$ 
It is highlighted that in the dimension: General physical state of health, a significant percentage $(50 \%)$, experiences difficulty in meeting the needs of their relatives, lack of energy and secondary discomfort to treatment still persist and continues to be a concern. Regarding the dimension: Family and social environment, also component of the quality of life, two areas of such domain reveal that the closeness with the couple and sexual satisfaction are affected since $27 \%$ of the population studied respectively responds not to feel Closeness and not be satisfied in its entirety. The emotional state, the third dimension that makes up the quality of life, shows that although most of the women who formed the present research study, they declare to experience great satisfaction in the way they are carrying their disease, even the general population exposes how the feelings of sadness, the nervousness; with a considerable percentage and the worry before the death, they are subjects that continue afflicting to them. Likewise, the fact that more than $90 \%$ of the population fears that their disease worsens at any time stands out.

When evaluating personal functioning capacity; which shows that only $36 \%$ of the study population feels very satisfied with their quality of life, the rest, which represents more than $62 \%$ does not present a full satisfaction. Similarly, the results highlight that a large part of the population is no longer able to enjoy the hobbies that pleased them. Other important data can be observed in this dimension such as: deficiencies in the capacity and job satisfaction, the ability to enjoy life and accept the disease. Finally, other concerns include the fact that only $9 \%$ of women feel attractive while the rest maintain varying degrees of insecurity. It is also found that $55 \%$ perceive pain and swelling in the arm corresponding to surgery (mastectomy) and 15\% suffer intense pain and swelling. However, the greatest concern found in this domain, with $70 \%$ incidence, is a great concern that a member of the family may suffer from the same disease.

According to the analysis of the results, it was possible to appreciate that the population in general maintains a quality of life committed, regularly and uncommitted, but few people report a good quality of life or nothing committed (Figure 2). Likewise, the information was analyzed through SPSS statistical analysis and a cross was carried out of the different variables interpreted as follows: The population that presents a regularly committed spiritual well-being also presents a quality of life regularly compromised, in the same way the population that has a little committed spiritual well-being presents a quality of life that is not very committed. What infers that if there is an adequate spiritual wellbeing therefore also a quality of life. The scientific advances of therapeutic techniques in people with breast cancer, in the last 50 years, continue to refer to mastectomy as the main method of treatment along with the multidisciplinary treatment of chemotherapy and radiotherapy have contributed to the survival of affected people. However, said surgical intervention implies a mutilation of the body and the psyche of the person, affecting the family structure and daily aspects in general since it brings with it psychosocial consequences, especially because of the cultural connotation that has been given to the breasts in the West, because they represent female sexuality and motherhood, so their mutilation implies the loss of the feminine entity and the "sense of being a woman". ${ }^{19}$ What can affect the spiritual well-being and the quality of life that together make up areas of great vulnerability of being Human or as mentioned by other studies is an essential part of the experience with cancer. ${ }^{20,21}$

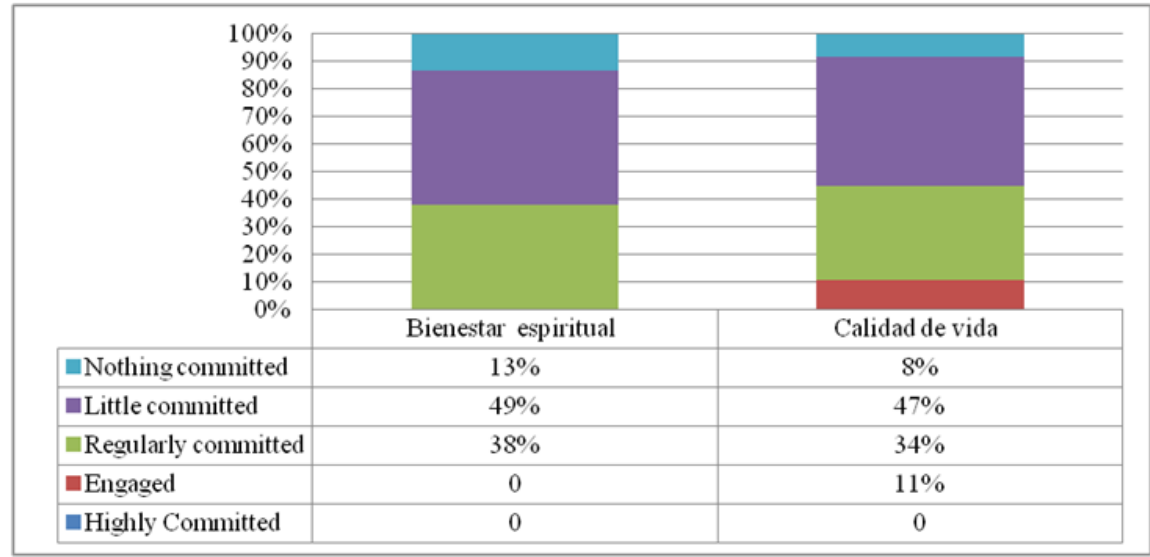

Figure 2 Spiritual well-being and quality of life of mastectomized older women. Fuente: Instrumento FACT-B y SP-12 (4² version) $n=102$.

In the present research study, it was identified that women mastectomized during old age, possess a degree of spiritual wellbeing and quality of life as regularly and little committed and only $8 \%$ nothing committed is to say a very good quality of life, These data do not coincide with the findings of Gallegos and Herrera, 2008; in whose results $88 \%$ of the population presented a good spiritual wellbeing. Neither agree with Rubén and col. who found a good quality of life in patients with breast cancer, presenting in $62 \%$ of the studied population. In the same way, the present study is related to the result obtained by Gallegos \& Herrera ${ }^{24}$ and Bethany et al. ${ }^{25}$ By pointing out that the indicator, "My illness has strengthened my faith" is found as a strengthening point in women mastectomized for breast cancer. This study indicates that more than $50 \%$ of the population has experienced strengthening their faith as a result of the disease. ${ }^{24,25}$
However, the in-depth analysis of the results showed that there are areas of difficulty for mastectomized women of advanced age that make them feel that aspect of difficulty, which is why the percentage that presents an integrated or very good quality of life is very low. which in turn coincide with other studies already published. For example, the study of Persistence of restrictions on quality of life from the first to the third year after diagnosis in women with breast cancer. It concludes that mastectomized women show deficiencies even over time in areas such as emotional, which in turn includes sexual satisfaction and adaptation to the role. These results agree with the present study since the emotional component of the studied population also presents these areas as deficient. ${ }^{25}$

The aforementioned study also emphasizes other persistent physical and social problems among the population, including: 
problems with the performance of physical activities, recreational activities, lymphedema and fear of the recurrence of the disease, which resembles the results obtained in the present study. On the other hand, it also points out that aspects of emotional well-being, which make up the quality of life of elderly mastectomized patients, reveal the persistence of feelings of sadness, nervousness, worry about death and fear of a worsening of the disease. These results also are related to what was studied at the Mexican Social Security Institute in 2011, where quality of life in Mexican women with breast cancer was studied in different clinical stages and its association with sociodemographic characteristics, co-morbid conditions and characteristics of the care process where different aspects of weakness were evidenced. ${ }^{26}$

Finally, this research demonstrates what other research has deduced regarding the close relationship between spiritual well-being and the quality of life of mastectomized women. First, it coincides with the study conducted by Bethany et al. ${ }^{25}$ They confirm that there is a positive correlation between spiritual well-being and quality of life in general. Since patients with a good level of spiritual well-being, in turn show an adequate level of quality of life in general. They also add that this information coincides with a number of previous investigations that have shown the high correlations between spiritual well-being and quality of life in patients with chronic diseases or lifethreatening diseases. ${ }^{23-27}$

The realization of this research study in elderly women who have undergone a mastectomy for breast cancer, allowed to identify, evaluate and finally determine how is the quality of life of the population studied, although it is not They can consider these results as conclusive. Because of the sample obtained, the proposed objectives could be achieved, offering a general overview of the study variables and, even more, the recognition of important aspects that can strengthen this quality of life and spiritual well-being through nursing interventions. and of the health team in a relevant way since these aspects are important for the health of the person, their family and the community, since they allow greater and better integration to the context that surrounds them with the "new opportunity of life" as they $\mathrm{He}$ is mentioned as a breast cancer survivor.

\section{Conclusion}

The majority of older women mastectomized for breast cancer, presented a spiritual well-being and a quality of life "little or regularly compromised". However, they can be with a full quality of life to work aspects of their lives that are still committed, which can general a quality of life committed or not at all pleasant and normally these dimensions are not covered within the professional care under a care plan established, however, having this background offers the opportunity for health personnel to take up these aspects in order to strengthen the professional and humanized care demanded by the population today as an a priori need.

Consequently, in the present study the importance of seeing the human being as a whole not only a body to which it is necessary to extirpate the disease through a surgical procedure, but also the diagnosis and the treatment have repercussions, was revealed in a subjective manner. Important in the physical, social, family, emotional and spiritual well-being that is to say the health in general, reason why the quality of life and the spiritual well-being must be seen like an occupation of the professional of nursing because they conform like dimensions of the important human being to attend.
Theoretical-practical implications in nursing: In the assistance practice the questionnaires related to spiritual well-being and quality of life can be useful to evaluate the answers obtained from the people attended with continuous nursing care after the treatments for its affectation as breast cancer and its effects side effects that can alter physical, emotional, social, spiritual well-being, that is, their quality of life and spirituality. Human needs that can and should be addressed by care programs aimed at improving the aspects most felt by affected people such as nervousness, fear among others manifested by the study population, in order that people may have an Adaptation integrated to your new health situation, bring to know the most important characteristics to carry a self-care, after your mastectomy and consequently we will have a more informed and committed population with your self-care, therefore with a better quality of life and spiritual well-being thus changing the results obtained today of quality of life committed, regularly committed and uncommitted in order to lead the person to their health as a dynamic quality that allows people the potential experience of physical, emotional, social, spiritual or of any other concern regarding your health with a prop the humanized care that should characterize health personnel, focusing the development of strategies for teaching people to stay stable and healthy despite the limitations that may have, as well as acquire a responsibility in their self-care and that does not depend only of hospital care.

\section{Financing details}

Self-financing

\section{Acknowledgments}

Thanks to the study participants, to the authorities of the State Center of Cancerology of Durango, to the authorities of the Nursing and Obstetrics Faculty of Durango, to the office of the nursing care program for women mastectomized for cancer of breast (PROCUIDEM) where it was possible to work more closely with the study population.

\section{Conflicts of interest}

The authors declare that there is no conflicts of interest.

\section{References}

1. Globocan: Global Cancer Observatory. IARC. 2018.

2. American Cancer Society. Data and Statistics on Cancer among Hispanics/Latinos 2015-2017. USA: American Cancer Society; 2015.

3. American Cancer Society. 2014.

4. Gallegos Alvarado M, Hernández Herrera DE. Spiritual Well-being in People with breast cancer. Nurse-patient relationship for a spiritual well-being as part of professional care. Spanish academic publishing house. 2012.

5. General Directorate of Health Information. Hospital expenses in the medical units of the Ministry of Health, according to the state, type of hospital and type of mastectomy. 2008.

6. Centers for Disease Control and Prevention (CDC). Breast cancer. Rates of breast cancer by race and ethnic group. 2013.

7. Ganz PA, Guadagnoli E, Landrum MB, et al. Breast Cancer in Older Women: Quality of Life and Phychosocial Adjustment in the 15 months after Diagnosis. J Clin Oncol. 2003;12(21):4027-4033. 
8. Escobar Rodríguez EY. Perception of the mastectomized woman about her body image at the National Institute of Neoplastic Diseases. Lima Peru. 2008

9. Guillen Llera F, Ruiperez Contreras I. Manual of Geriatrics. 3rd ed. Elseiver. 2002.

10. Valle Rivandeneyra RE, Zuñiga M, Tuzet C, et al. Symptomatology Depressive and quality of life in women patients with breast cancer. Annals of the Faculty of Medicine 2013;67(4):327-332.

11. WHO. Quality of Life Assessment Group. What quality of life?/WHO Group on quality of life. 1996;17(4):385-387.

12. Muñoz Bravo SF, Tose Vergara PA, Molano Galván DA. Experiences and self-care practices of women with breast cancer. Popayán Colombia 2006-2007. MED. 2013;22(2):137-148.

13. Jafari N, Farajzadegan Z, Zamani A, et al. Spiritual well-being and Quality of life in Iranian women with breast cancer undergoing radiation therapy. Supportive Care in Cancer. 2013;21(5):1219-1225.

14. World Health Organization. Frequently asked questions: How does WHO define health? 1948.

15. Rico Venegas RM, Catalina Martínez P, Romero Esquiváis C, et al Scientific Information for nursing care: Promotion of adult health in full. 2004.

16. MEXICO, Presidency of the Republic. Regulation of the General Health Law Regarding Research for Health. 2013.

17. Velarde Jurado E, Ávila Figueroa C. Evaluación de la calidad de vida. salud pública de méxico. 2002;44(4):349-361.

18. Peterman AH, Fitchett G, Brady MJ, et al. Measuring spiritual wellbeing in people with cancer: the functional assessment of chronic illness therapy-Spiritual Wellbeing Scale (FACIT-Sp). Ann Behav Med. 2002;24(1):49-58.
19. Cella D, Hernandez L. Bonomi AE, et al. Spanish language translation and initial validation of the functional assessment of cancer therapy quality of life instrument. Med Care. 1998;36(9):1407-1418.

20. http://www.facit.org/FACITOrg.

21. Airaldi MC. Sexuality and Relationships of Couple in Mastectomized Women of a Sample. Paraguay Eureka. 2010;7(1):143-162.

22. Cueva MF, Guili M, Dra Bianchi R, et al. Espiritualidad y Psiquiatría: La dimensión espiritual en la clínica y tratamiento de los problemas psiquiátricos. 2011.5 p.

23. Nuñez P, Enríquez D, Irarrazaval ME, et al. La espiritualidad en el paciente oncológico: una forma de nutrir la esperanza y fomentar un afrontamiento positivo a la enfermedad. Ajayu. 2011;10(5):84-100.

24. Gallegos M, Hernández DE. Bienestar Espiritual en pacientes con cáncer de mama identificado a través de la relación enfermera- paciente. Rev Enferm Inst Mex Seguro Soc. 2008;16(2):99-104.

25. Bethany T, Samuelson, MD, Erik K, et al. Changes in Spirituality and Quality of Life in Patients Undergoing Radiotherapy. Am J Hosp Palliat Care. 2013;29(6):451-454.

26. Sat-Muñoz D, Contreras-Hernández I, Balderas-Peña L, et al. Calidad de Vida en Mujeres Mexicanas con Cáncer de Mama en Diferentes Etapas Clínicas y su Asociación con Características SocioDemográficas, Estados Co-Mórbidos y Características del Proceso de Atención en el Instituto Mexicano del Seguro Social. Value in health. 2011;14(5):S133-S136.

27. Arndt V, Merx H, Stegmaier C, et al . Persistence of Restrictions in Quality of life from the first to the third year after diagnosis in women with breast cáncer. J Clin Oncol. 2005;23(22):4945-4953. 